\title{
Mobilidade de solutos em colunas de solo com água residuária doméstica e de suinocultura ${ }^{1}$
}

\author{
Joelma S. dos Santos², Vera L. A. de Lima², João C. F. Borges Júnior ${ }^{3}$, Leda V. B. D. Silva² \& Carlos A. V. de Azevedo²
}

\section{RESUMO}

Com o objetivo de avaliar o fator de retardamento, coeficiente de dispersão-difusão e curva de efluente dos íons cálcio, magnésio, sódio e potássio das águas residuárias de origem doméstica tratada e de suinocultura, real izou-se um experimento em laboratório com colunas de solos Argissolo Vermelho Amarelo e Neossolo Regolítico. Com o auxílio de frascos de Mariotte cerca de dois volumes de poros de água destilada foram passados nas colunas; em seguida, interligou-se outro frasco contendo as águas residuárias, doméstica e da suinocultura, o que lixiviou 3,75 volume de poros divididos em 25 alíquotas, totalizando 600 amostras. $0 \mathrm{~s}$ resultados permitiram concluir que os fatores de retardamento foram mais altos para 0 sódio no solo Argissolo Vermelho Amarelo e para o íon magnésio no N eossolo Regolítico, lixiviados com água residuária doméstica tratada. Em referência à água residuária da suinocultura, os maiores valores foram calculados para o íon magnésio, nos dois solos; quanto aos coeficientes de dispersão-difusão, os maiores valores foram registrados no N eossolo Regolítico, independentemente do tipo de água utilizada.

Palavras-chave: dinâmica de íons, fator de retardamento, coeficientes de difusão-dispersão

\section{Displacement of solutes in soil columns with domestic and swine raising wastewater}

\begin{abstract}
With the objective of evaluating the parameters of transport retardation factor, dispersion-diffusion coefficient and effluent curves of the íons calcium, magnesium, sodium and potassium, present in domestic and swine raising wastewater, an experiment was conducted in laboratory with columns of Red Yellow Argisol and Regolithic Fluvisol. W ith the aid of flasks of Mariotte around two pore volumes of distilled water were passed in the columns; soon after, another flask was interconnected containing the wastewaters which leached 3.75 volume of pores divided in 25 aliqnot, totaling 600 samples. The obtained results lead to the conclussion that the retardation factors were higher for the sodium in the Red Yellow Argisol and for the magnesium in Regolithic Fluvisol leached with treated domestic wastewater. In reference to the swine raising wastewater, the largest values were calculated for the ion magnesium, in the two soils; as for the dispersion-diffusion coefficients, the highest values were observed for Regolithic Fluvisol, independent of the type of water.
\end{abstract}

Key words: íons dinamic, retardation factor, diffusion-dispersion coefficients

1Parte da Dissertação da primeira autora apresentada à UFCG para obtenção do título de Mestre em Engenharia Agrícola

2UAEA/UFCG, Av. Aprígio Veloso 822, CEP 58429-140, Campina Grande, PB. Fone: (83) 2101-1312. E-mail: joelma_salles@yahoo.com.br; antuneslima@gmail.com; cazevedo@deag.ufcg.edu.br

3UFSJ. Caixa Postal 56, CEP 35701-970, Sete Lagoas, MG. Fone: (31) 3771-3305. E-mail: jcborges10@yahoo.com 


\section{INTRODUÇÃO}

A produção de resíduos oriundos das mais diversas atividades tem despertado grande inquietação, devido principalmente aos impactos que causa ao ambiente, sobretudo no que diz respeito à contaminação do solo, dos mananciais de superfície e subterrâneos, por diversos processos. Os cuidados com a preservação ambiental têm crescido em paralelo com o aumento da produção de resíduos gerados pela agroindústria, os quais podem ser utilizados na agricultura como forma de substituir parcialmente fertilizantes comerciais sintéticos.

Neste contexto, os fatores que justificam o uso de águas residuárias são a conservação da água disponível, sua grande disponibilidade, possibilidade do aporte e reciclagem de nutrientes (reduzindo a necessidade de fertilizantes químicos) além de concorrer para a preservação do meio ambiente. Dentre as águas utilizadas para reúso se destacam a água residuária da suinocultura e a doméstica (Medeiros et al., 2008). A utilização agrícola desse tipo de água residuária surge como alternativa para o seu descarte, com o benefício da reciclagem de nutrientes para as culturas (Cavallet et al., 2006).

A dinâmica da água no solo desloca os solutos para as distintas profundidades do perfil, movimento durante o qual uma parte dos solutos pode ser absorvida pelas plantas, outra perdida por percolação profunda e uma outra pode ser precipitada. O movimento de solutos no solo depende de fatores relacionados às propriedades do meio poroso e suas interações, propriedades do líquido percolante e as condições ambientais que influenciam nos parâmetros de transporte dos solutos. Dentre os fatores que influenciam o processo de migração e a retenção de substâncias químicas podem ser destacados: o tipo de solo, mineralogia, capacidade de troca catiônica, espécies de cátions absorvidos, velocidade de percolação e teor de matéria orgânica; concentração do contaminante, presença de outras substâncias na solução percolante, as condições hidrogeológicas e temperatura e $\mathrm{pH}$ do meio (Costa, 2002).

A lixiviação de íons varia com os atributos físicos do solo, como textura, estrutura, profundidade do perfil e, principalmente, porosidade. Entre os atributos químicos que afetam a lixiviação estão a capacidade de retenção de íons e o pH (Santos et al., 2002). A importância do estudo do transporte de solutos no solo reside no fato de que, a partir do conhecimento das propriedades e das interações de determinada substância química com o meio e de sua movimentação e persistência no solo, é possível se prever os riscos de contaminação e os impactos que ela pode causar ao meio ambiente (Piffer, 1989).

Dentro deste contexto, modelos de simulação podem proporcionar um entendimento melhor dos processos que ocorrem no solo, relativos ao deslocamento de solutos, constituindo-se em ferramentas aplicáveis a estudos de minimização de impactos ao ambiente. A especificidade da simulação da circulação da água no solo resulta da necessidade de se modelar as curvas de retenção da água e da condutividade hidráulica, envolvendo um conjunto reduzido de parâmetros específicos do solo em estudo (Neves et al., 2000). Para o sucesso da simulação e resolução das equações que predi- zem o deslocamento de solutos no solo, é necessária uma determinação realista dos parâmetros de transporte que influenciam na relação solo-soluto. Os parâmetros mais importantes que devem ser determinados para este fim, são a velocidade da água no poro, os coeficientes de difusão-dispersão e o fator de retardamento, este último definido por Valocchi (1984) como sendo a relação entre a velocidade do soluto reativo e a velocidade média da água no poro revelando, portanto, as interações entre as fases líquida e sólida que ocorrem no trajeto da solução deslocadora no solo. O coeficiente de difusão-dispersão é um parâmetro físico que considera a difusão iônica e a dispersão mecânica na solução do solo (Genuchten \& Wierenga, 1986).

Na última década, algumas pesquisas têm sido desenvolvidas com o uso de águas residuárias, mas ainda são pouco frequentes na literatura trabalhos que apresentam dados sobre os impactos negativos provocados pelo uso dessas águas ao solo e aos mananciais hídricos. Dentre os artigos que tratam sobre o transporte de solutos em colunas de solo destacam os de Melo et al. (2006); Agourakis et al. (2006); Gomes et al. (2004), dentre outros; no entanto, nenhuma pesquisa foi identificada sobre o deslocamento de cátions provenientes de águas residuárias domésticas e da suinocultura, em colunas de solo. Neste contexto, o trabalho teve como objetivo determinar os fatores de retardamento, coeficientes dispersivos-difusivos e as curvas de efluente para os íons cálcio, magnésio, sódio e potássio presentes em água residuária doméstica e de suinocultura, em colunas de solo de distintas texturas.

\section{MATERIAL E MÉTODOS}

Os ensaios foram realizados no Laboratório de Engenharia de Irrigação e Drenagem, LEID, da Universidade Federal de Campina Grande, UFCG, no município de Campina Grande, $\mathrm{PB}$, com as seguintes coordenadas geográficas: $7^{\circ} 15^{\prime} 18^{\prime \prime}$ latitude sul, $35^{\circ} 52^{\prime} 28^{\prime \prime}$ de longitude oeste, com altitude média de $550 \mathrm{~m}$.

Foram utilizadas amostras de um Argissolo Vermelho Amarelo e um Neossolo Regolítico (Santos et al., 2006), coletadas na profundidade de 0 a $20 \mathrm{~cm}$, caracterizadas física e quimicamente (Tabela 1) conforme EMBRAPA (1997).

Nos ensaios se utilizaram dois tipos de água residuária, esgoto doméstico tratado e efluente de suinocultura. A água residuária de origem doméstica foi proveniente da Estação de Tratamento Biológico de Esgotos (EXTRABES) da Universidade Federal de Campina Grande, UFCG. O esgoto foi tratado através do sistema UASB (Reator Anaeróbico de Fluxo Ascendente), que removeu a matéria orgânica e portógenos. A água residuária oriunda de atividades de suinocultura foi cedida por granja de criação de suínos, localizada no município de Puxinanã, PB, e coletada diretamente da lagoa de disposição de efluentes. Na Tabela 2 se encontra a caracterização das águas residuárias, feita no Laboratório de Irrigação e Salinidade, LIS, da Universidade Federal de Campina Grande, através de metodologias descritas no manual da EMBRAPA (1997). 
Tabela 1. Caracterização física e química das amostras dos solos utilizados nos ensaios

\begin{tabular}{|c|c|c|}
\hline Características & \multicolumn{2}{|c|}{ Argissolo Vermelho Amarelo Neossolo Regolítico } \\
\hline Areia grossa $\left(\mathrm{g} \mathrm{kg}^{-1}\right)$ & 339 & 669 \\
\hline Areia fina $\left(\mathrm{g} \mathrm{kg}^{-1}\right)$ & 298 & 257 \\
\hline Silte $\left(\mathrm{g} \mathrm{kg}^{-1}\right)$ & 88 & 54 \\
\hline Argila $\left(\mathrm{g} \mathrm{kg}^{-1}\right)$ & 275 & 20 \\
\hline Argila dispersa $\left(\mathrm{g} \mathrm{kg}^{-1}\right)$ & 51 & 0,0 \\
\hline Grau de floculação $\left(\mathrm{kg} \mathrm{dm}^{-3}\right)$ & 815 & 1000 \\
\hline Densidade do solo $\left(\mathrm{g} \mathrm{cm}^{-3}\right)$ & 1,14 & 1,52 \\
\hline $\begin{array}{l}\text { Densidade das partículas } \\
\left(\mathrm{g} \mathrm{cm}^{-3}\right)\end{array}$ & 2,65 & 2,66 \\
\hline Porosidade total & 0,57 & 0,43 \\
\hline $\mathrm{pH}$ & 5,16 & 4,97 \\
\hline Fósforo (mg dm-3) & 3,60 & 4,97 \\
\hline Potássio $\left(\mathrm{mg} \mathrm{dm}^{-3}\right)$ & 156,0 & 43,10 \\
\hline Sódio $\left(\mathrm{cmol}_{\mathrm{c}} \mathrm{dm}^{-3}\right)$ & 0,06 & 0,06 \\
\hline Cálcio $\left(\mathrm{cmol}_{\mathrm{c}}^{\mathrm{c}} \mathrm{dm}^{-3}\right)$ & 1,50 & 0,55 \\
\hline Magnésio $\left(\mathrm{cmol}_{\mathrm{c}} \mathrm{dm}^{-3}\right)$ & 0,80 & 0,30 \\
\hline $\mathrm{H}^{+}+\mathrm{AR}^{2+}\left(\mathrm{cmol}_{\mathrm{c}}^{\mathrm{c}} \mathrm{dm}^{-3}\right)$ & 6,93 & 1,65 \\
\hline Enxofre (mg dm $\left.\mathrm{m}^{-3}\right)$ & 8,87 & 7,84 \\
\hline Cobre $\left(\mathrm{mg} \mathrm{dm}^{-3}\right)$ & 0,265 & 0,33 \\
\hline Ferro $\left(\mathrm{mg} \mathrm{dm}^{-3}\right)$ & 49,56 & 15,33 \\
\hline Zinco (mg dm ${ }^{-3}$ ) & 0,80 & 0,85 \\
\hline Manganês (mg dm ${ }^{-3}$ ) & 5,10 & 4,32 \\
\hline Boro $\left(\mathrm{mg} \mathrm{dm}^{-3}\right)$ & 0,45 & 0,14 \\
\hline$M O^{1}\left(\mathrm{~g} \mathrm{~kg}^{-1}\right)$ & 16,53 & 4,06 \\
\hline $\mathrm{CTC}^{2}\left(\mathrm{cmol}_{\mathrm{c}} \mathrm{dm}^{-3}\right)$ & 9,79 & 2,67 \\
\hline $\mathrm{SB}^{3}\left(\mathrm{cmol}_{\mathrm{c}} \mathrm{dm}^{-3}\right)$ & 2,76 & 1,02 \\
\hline
\end{tabular}

${ }^{1}$ M.O.: Matéria orgânica; ${ }^{2} \mathrm{CTC}$ : Capacidade de troca catiônica; ${ }^{3} \mathrm{SB}$ : Soma de bases trocáveis

Tabela 2. Caracterização da água residuária

\begin{tabular}{lcc}
\hline \multirow{2}{*}{ Caracterização } & \multicolumn{2}{c}{ Valores } \\
\cline { 2 - 3 } pH & Doméstica & Suinocultura \\
Condutividade elétrica $\left(\mathrm{dS} \mathrm{m} \mathrm{m}^{-1}\right)$ & 7,28 & 8,16 \\
Cálcio $\left(\mathrm{mmol}_{\mathrm{c}} \mathrm{L}^{-1}\right)$ & 1,320 & 5,65 \\
Magnésio $\left(\mathrm{mmol}_{\mathrm{c}} \mathrm{L}^{-1}\right)$ & 0,87 & 2,02 \\
Sódio $\left(\mathrm{mmol}_{\mathrm{c}} \mathrm{L}^{-1}\right)$ & 3,41 & 9,90 \\
Potássio $\left(\mathrm{mmol}_{\mathrm{c}} \mathrm{L}^{-1}\right)$ & 6,14 & 27,58 \\
Sulfatos $\left(\mathrm{mmol}_{\mathrm{c}} \mathrm{L}^{-1}\right)$ & 0,53 & 7,39 \\
Carbonatos $\left(\mathrm{mmol}_{\mathrm{c}} \mathrm{L}^{-1}\right)$ & 0,0 & 0,0 \\
Bicarbonato $\left(\mathrm{mmol}_{\mathrm{c}} \mathrm{L}^{-1}\right)$ & 0,00 & 1,40 \\
Cloretos $\left(\mathrm{mmol}_{\mathrm{c}} \mathrm{L}^{-1}\right)$ & 8,26 & 13,18 \\
RAS* mmol $\left(\mathrm{L}^{-1}\right)^{0,5}$ & 5,62 & 28,17 \\
\hline
\end{tabular}

*Relação de adsorção de sódio

Após secado ao ar e passado em peneira de $2 \mathrm{~mm}$ de malha, foram preparadas colunas de cada tipo de solo. Utilizaram-se, no experimento, colunas de vidro com $26 \mathrm{~cm}$ de altura e $6 \mathrm{~cm}$ de diâmetro interno; na extremidade inferior foram colocados dois círculos, um feito com tela de nylon e o outro círculo de lã de vidro, para sustentação do material visando evitar a perda de solo durante os ensaios. Os discos foram presos à coluna com o auxílio de uma braçadeira de metal, de diâmetro ligeiramente superior ao da coluna; na parte superior da coluna, sobre o solo, colocou-se lã de vidro, de modo a proporcionar melhor distribuição do líquido a ser percolado e garantir a uniformidade de infiltração da solução no solo.

As colunas foram preenchidas com material de solo até a altura de $20 \mathrm{~cm}$. O preenchimento das colunas foi feito de forma a manter a densidade de cada solo o mais próximo possível dos solos no campo, determinada em laboratório; a cada $3 \mathrm{~cm}$ de solo colocado na coluna, os solos foram acondicionados com o auxílio de um disco de madeira de diâmetro inferior ao diâmetro interno da coluna, sendo o disco provido de pregos, visando-se ao revolvimento do solo.

Depois de preenchida com solo cada coluna era colocada em um recipiente de plástico preenchido até $2 / 3$ da altura da coluna de solo com água destilada; as colunas eram deixadas em repouso durante $36 \mathrm{~h}$. Depois das colunas serem saturadas, eram fixadas em suporte vertical e interligadas a frascos de Mariotte para a aplicação de água destilada, correspondente a cerca de 2 volumes de poros, mantendo constante uma carga hidráulica de $4 \mathrm{~cm}$. Após a infiltração da água destilada no solo, os frascos de Mariotte eram substituídos por outros contendo a água residuária para a passagem de 3,75 volumes.

Para cada coluna foram determinadas as características físico-hídricas: volume de poros, fluxo e velocidade de avanço. $\mathrm{O}$ volume de poros de cada coluna $(\mathrm{Vp})$ foi determinado pela relação (Eq. 1):

$$
\mathrm{V}_{\mathrm{p}}=\pi \mathrm{r}^{2} \mathrm{~h}\left(1-\frac{\mathrm{Ds}}{\mathrm{Dp}}\right)
$$

em que

$\mathrm{r}$ - raio da coluna, $\mathrm{cm}$

$\mathrm{h}$ - comprimento da coluna, $\mathrm{cm}$

Ds - densidade do solo, $\mathrm{g} \mathrm{cm}^{-3}$

Dp - densidade das partículas, $\mathrm{g} \mathrm{cm}^{-3}$

$\mathrm{O}$ fluxo de cada coluna foi calculado por meio da Eq. 2

$$
\mathrm{q}=\frac{\mathrm{Q}}{\mathrm{A}}=\frac{\mathrm{Ve}}{\mathrm{At}}
$$

em que

$$
\begin{aligned}
& \mathrm{q}-\text { fluxo, } \mathrm{cm} \mathrm{h}^{-1} \\
& \mathrm{Q}-\text { vazão, } \mathrm{cm}^{3} \mathrm{~h}^{-1} \\
& \mathrm{~A}-\text { seção transversal da coluna, } \mathrm{cm}^{2} \\
& \mathrm{Ve} \text { - volume total de efluente, } \mathrm{cm}^{3} \\
& \mathrm{t} \quad \text { - intervalo de tempo para coletar o volume Ve } \mathrm{h}
\end{aligned}
$$

A velocidade de avanço da solução percolante para cada solo foi definida através da Eq. 3:

$$
\mathrm{V}_{\mathrm{f}}=\frac{\mathrm{q}}{\alpha}
$$

em que

$$
\begin{aligned}
& \text { Vf }- \text { velocidade de avanço, } \mathrm{cm} \mathrm{h}^{-1} \\
& \mathrm{q}-\text { fluxo, } \mathrm{cm} \mathrm{min}^{-1} \\
& \alpha-\text { porosidade total, } \mathrm{cm}^{3} \mathrm{~cm}^{-3}
\end{aligned}
$$

Cada ensaio consistiu em 3 repetições em que era aplicado, em cada um, 3,75 número de volumes de poros de água residuária, divididos em 25 alíquotas de 0,15 volume de poros do efluente por cada coluna. O efluente era coletado em proveta e acondicionado em frascos plásti- 
cos mantidos fechados, armazenados sob refrigeração e encaminhados ao laboratório, acomodados em caixa de isopor.

Determinaram-se, nas 600 amostras de efluente, as concentrações dos íons potássio e sódio por fotometria de emissão de chama e as concentrações de cálcio e magnésio, por titulação (EMBRAPA, 1997).

Determinaram-se os parâmetros de transporte fator de retardamento e coeficiente de difusão-dispersão, utilizando-se o modelo computacional DISP (Programa para cálculo dos parâmetros de transporte de solutos no solo em deslocamento de fluidos miscíveis), desenvolvido no Departamento de Engenharia Agrícola da Universidade Federal de Viçosa, por Borges Júnior \& Ferreira (2006); com ele se ajustaram as curvas dos efluentes para os íons cálcio, magnésio, sódio e potássio.

\section{RESULTADOS E DISCUSSÃO}

Os valores médios das características físico-hídricas volume de poros, fluxo e velocidade de avanço da solução dos solos Argissolo Vermelho Amarelo e Neossolo Regolítico que receberam tratamento com água residuária doméstica tratada e de suinocultura, se encontram na Tabela 3 .

Tabela 3. Valores médios das características volume de poros, fluxo e velocidade de avanço da solução nas colunas de solo, verificados para os ensaios com água residuária doméstica tratada e de suinocultura

\begin{tabular}{lcc}
\hline \multirow{2}{*}{ Características físico-hídricas } & \multicolumn{2}{c}{ Solo } \\
\cline { 2 - 3 } & Argissolo Vermelho Amarelo Neossolo Regolítico \\
Volume de poros $\left(\mathrm{cm}^{3}\right)$ & 305,93 & 235,81 \\
Fluxo $\left(\mathrm{cm} \mathrm{h}^{-1}\right)$ & 17,25 & 39,17 \\
Velocidade de avanço $\left(\mathrm{cm} \mathrm{h}^{-1}\right)$ & 31,89 & 93,93 \\
& Água de suinocultura \\
Volume de poros $\left(\mathrm{cm}^{3}\right)$ & 312,71 & 235,81 \\
Fluxo $\left(\mathrm{cm} \mathrm{h}^{-1}\right)$ & 15,98 & 29,60 \\
Velocidade de avanço $\left(\mathrm{cm} \mathrm{h}^{-1}\right)$ & 28,90 & 70,98 \\
\hline
\end{tabular}

Verifica-se, na Tabela 3, que os volumes de poros encontrados na água residuária doméstica e na água da suinoculturada, foram mais elevados para o Argissolo Vermelho Amarelo, resultados esses coerentes com a relação entre as densidades verificadas neste solo, conforme apresentadas na Tabela 1. O fluxo e, consequentemente a velocidade de avanço, apresentaram a mesma tendência.

$\mathrm{Na}$ Tabela 4 tem-se os resultados médios obtidos para fator de retardamento, desvios padrão e coeficientes de variação, para os íons estudados.

$\mathrm{O}$ fator de retardamento expressa as interações entre as fases líquida e sólida que ocorrem durante a percolação da solução deslocadora no solo, Tabela 4. Os maiores valores encontrados para o fator de retardamento foram para os cáti-
Tabela 4. Valores médios, desvios padrão $(\delta)$ e coeficientes de variação $(C V)$, relativos aos fatores de retardamento $(R)$, calculados para as curvas de efluente de concentrações relativas aos íons cálcio, magnésio, sódio e potássio

\begin{tabular}{|c|c|c|c|c|c|c|}
\hline & \multicolumn{3}{|c|}{ Argissolo Vermelho Amarelo } & \multicolumn{3}{|c|}{ Neossolo Regolítico } \\
\hline & $R$ & $\delta$ & CV (\%) & $\mathbf{R}$ & $\delta$ & CV (\%) \\
\hline & \multicolumn{6}{|c|}{ Água doméstica tratada } \\
\hline Cálcio & 1,696 & 0,100 & 5,90 & 1,669 & 0,096 & 5,80 \\
\hline Magnésio & 2,024 & 0,020 & 1,0 & 1,914 & 0,051 & 2,70 \\
\hline Sódio & 2,335 & 0,115 & 4,9 & 1,485 & 0,045 & 3,10 \\
\hline \multirow[t]{2}{*}{ Potássio } & 1,687 & 0,061 & 3,6 & 1,255 & 0,152 & 12,10 \\
\hline & \multicolumn{6}{|c|}{ Água de suinocultura } \\
\hline Cálcio & 1,589 & 0,171 & 10,80 & 1,514 & 0,008 & 0,50 \\
\hline Magnésio & 2,112 & 0,130 & 6,20 & 1,680 & 0,041 & 2,50 \\
\hline Sódio & 1,688 & 0,045 & 2,70 & 1,364 & 0,091 & 6,70 \\
\hline Potássio & 1,672 & 0,032 & 1,90 & 1,369 & 0,048 & 3,50 \\
\hline
\end{tabular}

ons bivalentes, cálcio e magnésio, para o Neossolo Regolítico lixiviado com ambas as águas, visto que, quanto maior a carga maior também a força de atração do íon pela fração coloidal do solo. $\mathrm{O}$ fator de retardamento, por ser uma característica que retrata a capacidade do solo em reter os solutos à medida em que o fluxo de massa avança, depende das interações entre as fases líquida e sólida que ocorrem durante a percolação (Melo et al., 2006). Menores valores de $\mathrm{R}$ foram encontrados para o potássio e para o cálcio no Argissolo Vermelho Amarelo, quando lixiviado com água residuária doméstica e da suinocultura respectivamente.

Percebe-se que, quanto menor a velocidade de avanço da solução na coluna de solo, maior é o tempo de contato entre os íons e os colóides do solo, promovendo maior oportunidade de retenção dos solutos, causando aumento no fator de retardamento, como observado para o solo Argissolo Vermelho Amarelo, o qual apresenta velocidade de avanço de apenas $1 / 3$ da encontrada para 0 Neossolo Regolítico.

Valores médios de coeficientes de dispersão-difusão, desvios padrão e coeficientes de variação se encontram na Tabela 5.

Tabela 5. Valores médios, desvios padrão $(\delta)$ e coeficientes de variação (CV), relativos aos coeficientes de dispersão-difusão (D), calculados para a curva de efluente de concentrações relativas aos íons cálcio, magnésio, sódio e potássio

\begin{tabular}{lcccccc}
\hline & \multicolumn{3}{c}{ Argissolo Vermelho Amarelo } & \multicolumn{3}{c}{ Neossolo Regolítico } \\
\cline { 2 - 7 } & D & $\delta$ & CV (\%) & D & $\delta$ & CV (\%) \\
Cálcio & 64,186 & 2,013 & 3,10 & 270,123 & 76,406 & 26,90 \\
Magnésio & 90,953 & 39,177 & 39,70 & 276,896 & 61,356 & 21,69 \\
Sódio & 144,904 & 2,675 & 1,90 & 216,036 & 22,698 & 10,4 \\
Potássio & 45,957 & 10,559 & 22,7 & 268,833 & 58,817 & 21,30 \\
\hline \multicolumn{7}{c}{} \\
Cálcio & 180,343 & 34,609 & 18,80 & 391,776 & 59,991 & 15,10 \\
Magnésio & 153,803 & 5,947 & 3,90 & 196,249 & 22,445 & 11,40 \\
Sódio & 71,542 & 3,960 & 5,50 & 155,340 & 30,052 & 18,90 \\
Potássio & 91,167 & 17,113 & 18,40 & 234,591 & 28,247 & 11,90 \\
\hline
\end{tabular}


Os coeficientes de dispersão-difusão (D) no solo Neossolo Regolítico foram superiores aos do Argissolo Vermelho Amarelo para todos os íons estudados (Tabela 5). Valores mais elevados dos coeficientes de difusão-dispersão estão relacionados às menores inclinações das curvas de efluente $\mathrm{e}$, consequentemente, ao alargamento da faixa de mistura entre as soluções deslocadora e deslocada no perfil do solo, tornando os acréscimos na concentração relativa, baixos, para acréscimos no número de volume de poros (Nielsen \& Biggar, 1962).

A menor velocidade de avanço da solução no Argissolo Vermelho Amarelo é uma das possíveis causas para os seus menores valores de coeficiente de dispersão difusão, para este solo. O coeficiente de dispersão difusão pode ser indicativo da capacidade do solo em reter determinado soluto a medida em que a frente de umedecimento da solução aplicada avança no perfil do solo (Engler et al., 2008).

Os coeficientes de variação referentes aos coeficientes de dispersão-difusão dos íons variaram entre 3,90 e 18,90; segundo Santos et al. (2008), amplitudes entre 10 e $20 \%$ são admitidas como adequadas e indicam precisão satisfatória dos dados.

O coeficiente de dispersão-difusão (D) para todos os íons no Argissolo Vermelho Amarelo lixiviado com água da suinocultura, apresentou valores mais elevados em relação ao mesmo solo com esgoto doméstico tratado; este fato pode ser atribuído ao elevado teor desses solutos contido na solução deslocadora oriunda da atividade de suinocultura; também se percebe correlação direta dos valores observados para coeficiente de dispersão-difusão com a velocidade da solução; o transporte dispersivo está diretamente relacionado com a velocidade de avanço da solução. Martinez et al. (2001), ao estudarem o efeito da competição catiônica no fator de retardamento e no coeficiente de dispersão-difusão de zinco e cobre no solo, verificaram que as baixas velocidades de avanço das soluções proporcionaram os baixos valores de coeficiente de dispersão-difusão no solo; a mesma tendência é constatada neste trabalho quando se comparam as Tabelas 3 e 5 .

Nas Figuras 1 a 2 estão as curvas de efluentes obtidas com os solos Argissolo Vermelho Amarelo e Neossolo Regolítico, ajustadas por meio do programa DISP aos dados obtidos em laboratório, para a água residuária doméstica.

A análise do comportamento da curva de efluente ou curva de eluição, permite identificar as interações da solução com a fração sólida do solo. Para Nielsen \& Biggar (1962) quando na curva o valor correspondente à concentração relativa de 0,5 é maior que 1 número de volume de poros, a curva de efluente se apresentará deslocada para a direita, indicando retardamento na velocidade de avanço do soluto em relação à velocidade média de avanço da solução deslocadora. Esta análise identifica que, ao escoar através do perfil do solo, parte do soluto é adsorvi$\mathrm{da}$, indicando um fator de retardamento maior que a unidade. Desta análise constata-se que quanto mais o valor do número de volume de poros se distancia do valor unitário para a concentração relativa de 0,5 , maior será a interação soluto-solo.
A.

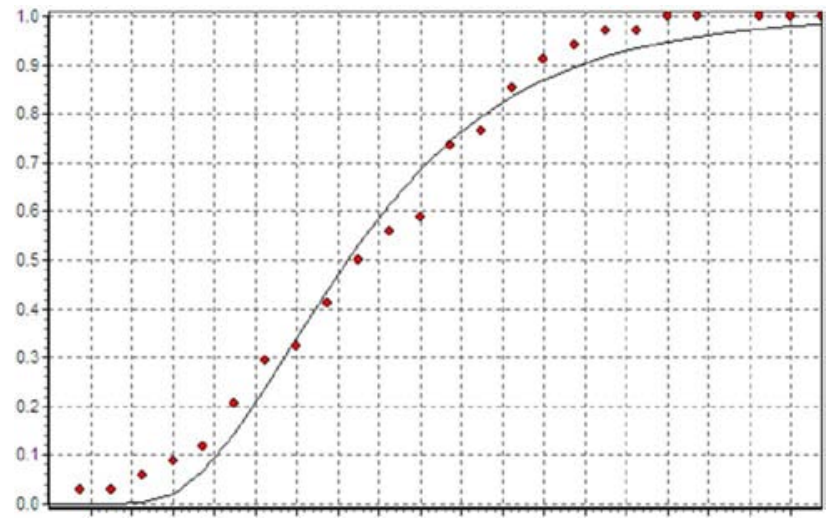

B.

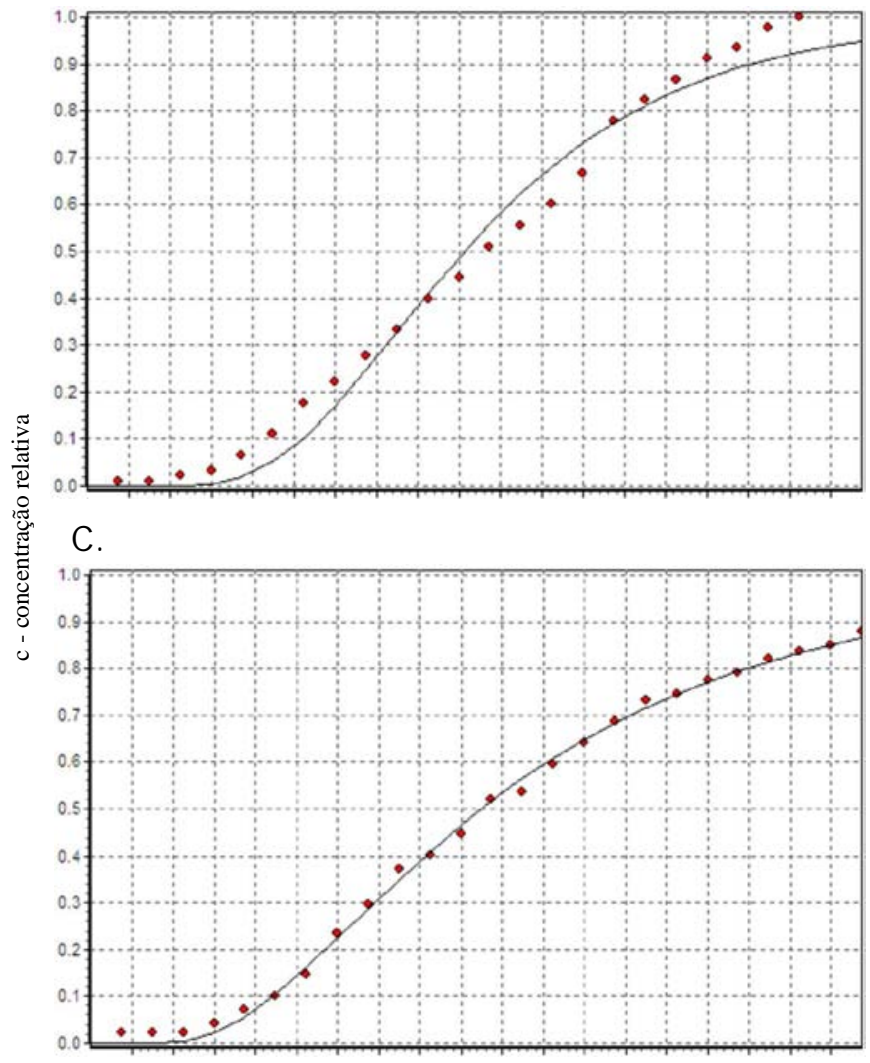

D.

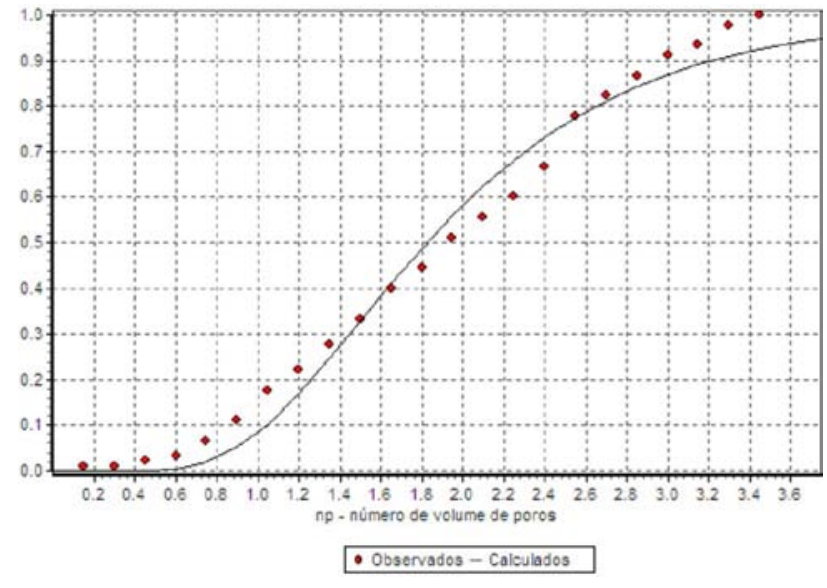

Figura 1. Curvas de efluente para o cálcio (A), magnésio (B), sódio (C) e potássio (D) ajustadas utilizando-se o programa computacional D ISP, para o solo Argissolo Vermelho Amarelo e água residuária doméstica tratada 
A.

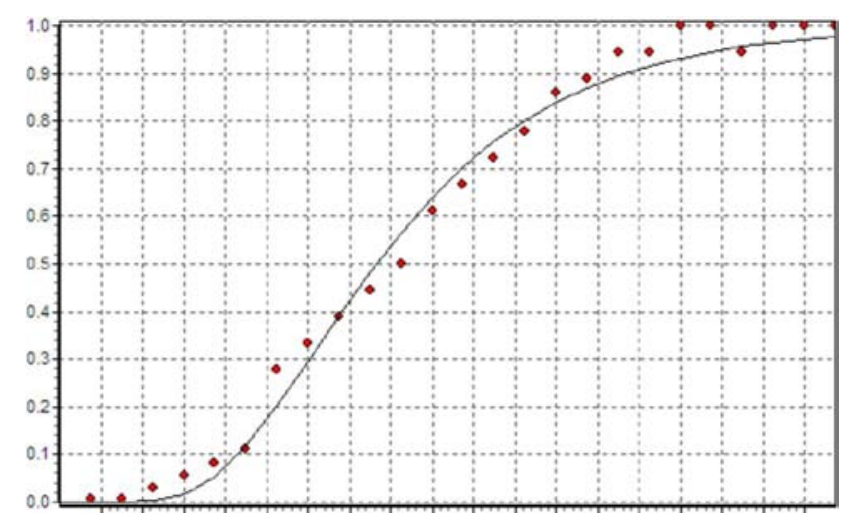

B.

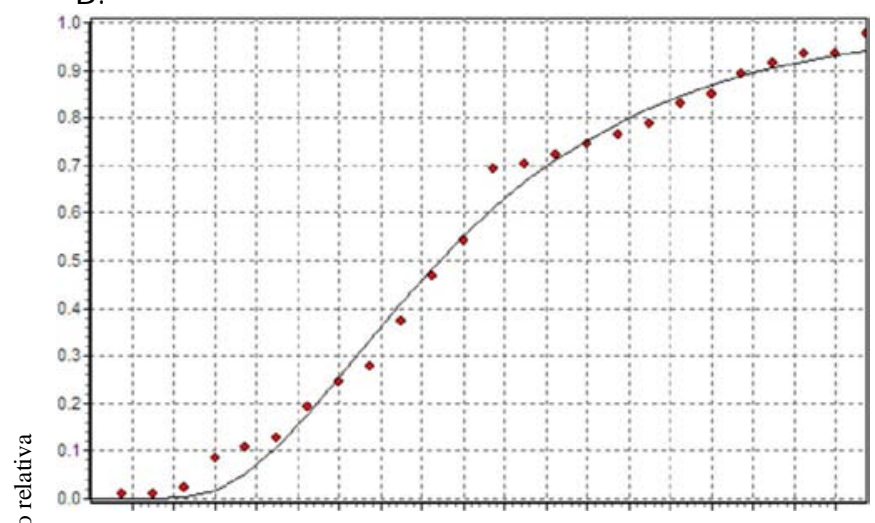

C.
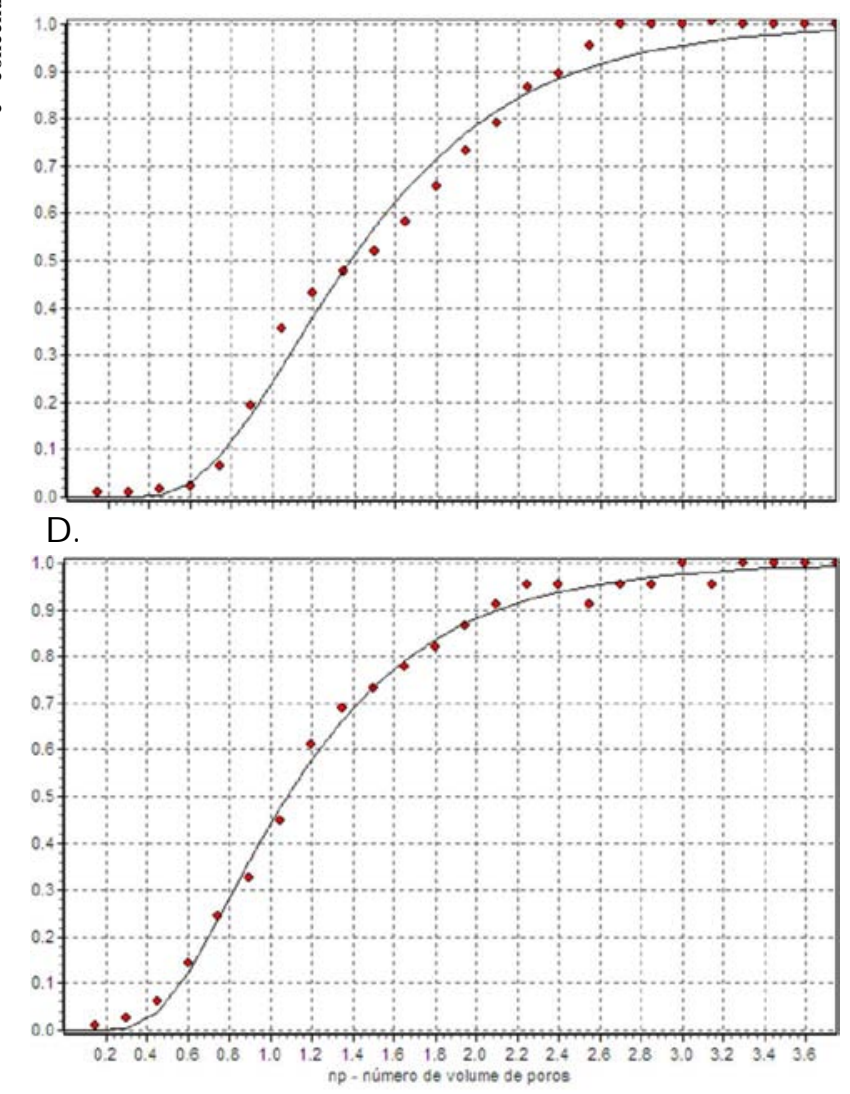

- Observados - Calculados

Figura 2. Curvas de efluente para o cálcio (A), magnésio (B), sódio (C) e potássio (D), ajustadas utilizando-se o programa computacional DISP, para o solo N eossolo Regolítico e água residuária doméstica tratada
Comparando-se as curvas de efluentes para o cálcio obtidas para o Argissolo Vermelho Amarelo e para o Neossolo Regolítico, Figuras 1A e 2A, respectivamente, percebe-se que a concentração relativa de 0,5 é menor que 1 número de volume de poros de maneira geral, indicando baixa interação deste íon com o solo. A mesma tendência da curva de eluição para o solo Argissolo Vermelho-Amarelo distrófico com calcário foi observada por Gomes et al. (2004).

Nas Figuras 1B e 2C observa-se que as curvas de distribuição de efluente no Argissolo Vermelho Amarelo para os íons magnésio e sódio se apresentam deslocadas para a direita, indicando que esses íons foram retidos no solo com intensidade maior em relação aos íons de cálcio e potássio (1A e 1D).

O efeito de adsorção do íon magnésio no Neossolo Regolítico pode ser observado pela curva de distribuição de efluente desse íon (Figura 2B), o que reflete a obtenção do maior valor encontrado para o fator de retardamento para este íon, em relação ao cálcio, sódio e potássio.

Atentando-se para a curva de efluente do potássio (Figura 2D) percebe-se que, quando a concentração relativa se aproxima de 0,5 , o valor correspondente para o volume de poros também se aproxima de 1, indicando a baixa interação soluto-solo. Quando o valor correspondente à concentração relativa de 0,5 é 1 volume de poros, significa que o soluto não está interagindo com a fração coloidal do solo.

Os coeficientes de determinação $\left(R^{2}\right)$ para as curvas de efluentes foram superiores a 95\%, indicando correlação adequada entre os valores experimentais e os valores ajustados pelo programa DISP. Também indica menor dispersão dos íons durante os ensaios. Gomes et al. (2004) em experimento realizado com colunas de solo argiloso e arenoso lixiviadas com água residuária de frigorífico, obtiveram ajuste das curvas de efluentes de nitrato através do programa CXTFIT com coeficiente de determinação acima de $80 \%$.

Nas Figuras 3 a 4 estão as curvas de efluentes obtidas com os solos Argissolo Vermelho Amarelo e Neossolo Regolítico, ajustadas por meio do programa DISP aos dados obtidos em laboratório, para as águas residuárias da suinocultura.

Observa-se na Figura 3B, na representação da curva de efluente do íon magnésio, lento aumento da concentração relativa $(\mathrm{C} / \mathrm{Co})$, indicando maior mistura da solução deslocada com a solução do solo. O deslocamento da curva para a direita reflete o maior valor encontrado para o fator de retardamento, fato observado também para o magnésio na água residuária doméstica, porém com menor intensidade, Figura 1B.

Comparando-se as curvas de eluição do sódio no solo Argissolo Vermelho Amarelo, Figuras 1C e 4C, percebe-se diferença a partir de 0,5 volume de poros. Quando a água residuária de suinocultura alcança a seção transversal inferior da coluna, a relação $\mathrm{C} / \mathrm{Co}$ cresce rapidamente até atingir valor igual ao do fluido deslocador e, de maneira mais lenta, o deslocamento da curva do $\mathrm{Na}^{+}$existente no efluente de esgoto doméstico tratado. Esses resultados são reflexo, para este íon, das concentrações contidas nessas soluções.

Na Figura 4 as curvas de distribuição de efluentes do Neossolo Regolítico mostraram, de modo geral, tendência de deslocamento para a direita $(\mathrm{R}>1)$, indicando a interação solo-soluto. 
A.

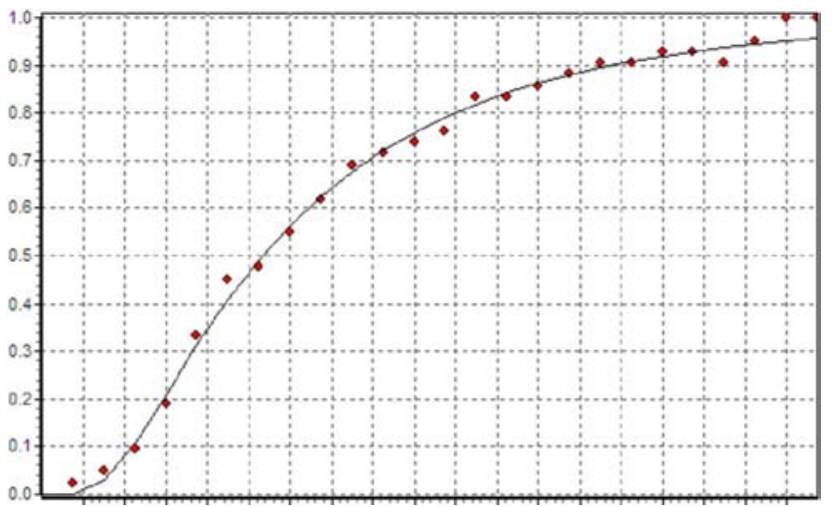

B.

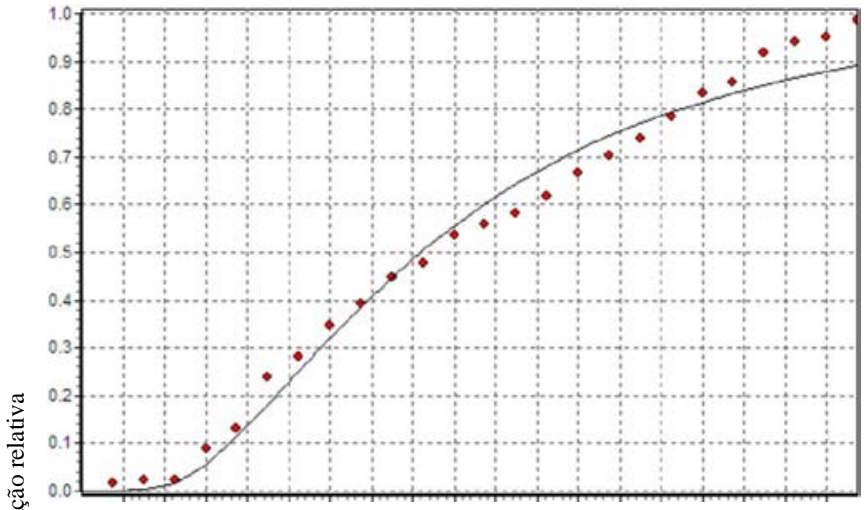

C.

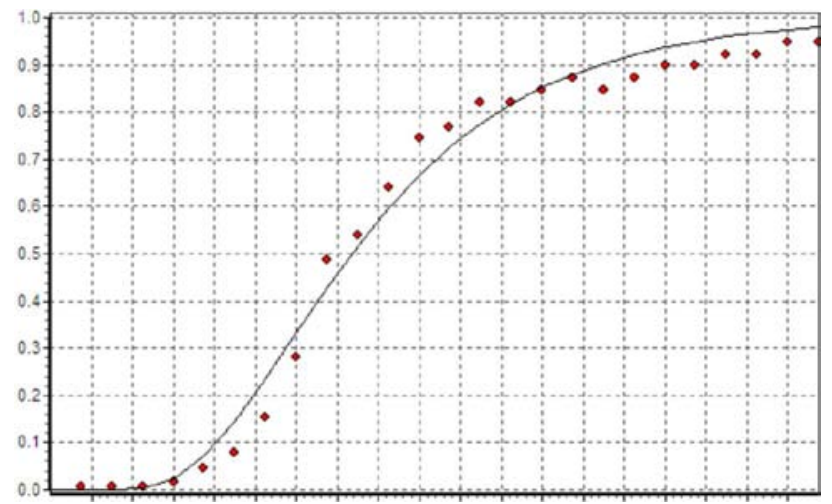

D.

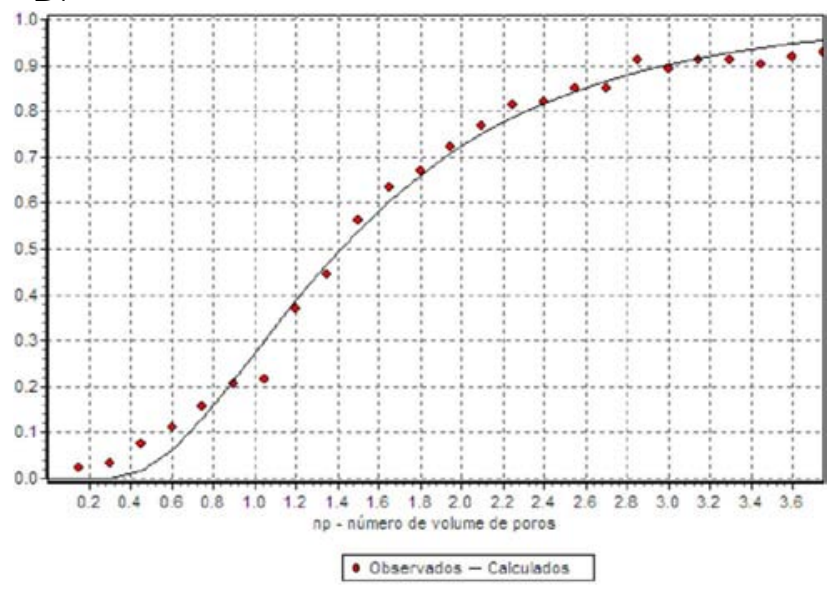

Figura 3. Curvas de efluente para o cálcio (A), magnésio (B), sódio (C) e potássio (D), ajustadas utilizando-se o programa computacional DISP, para o solo Argissolo Vermelho Amarelo e água residuária de suinocultura
A.

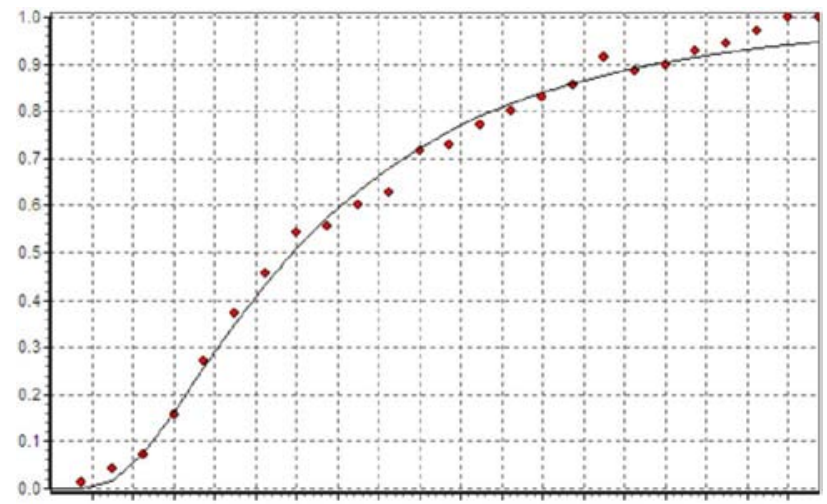

B.

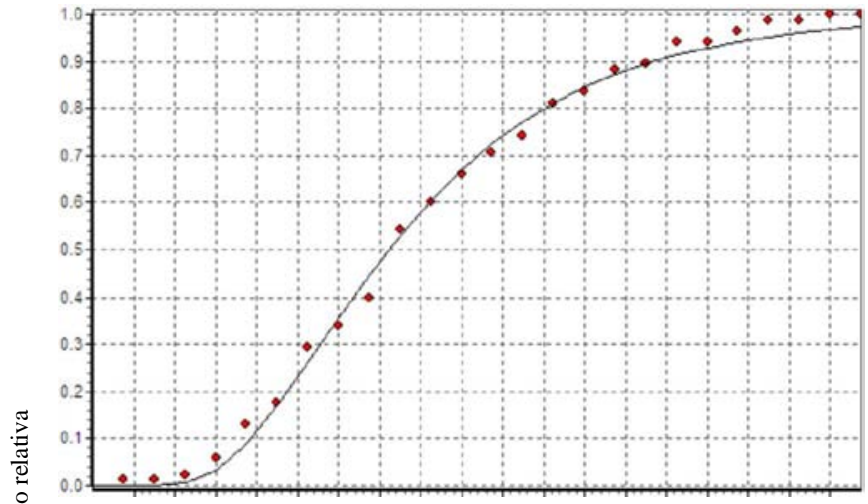

C.

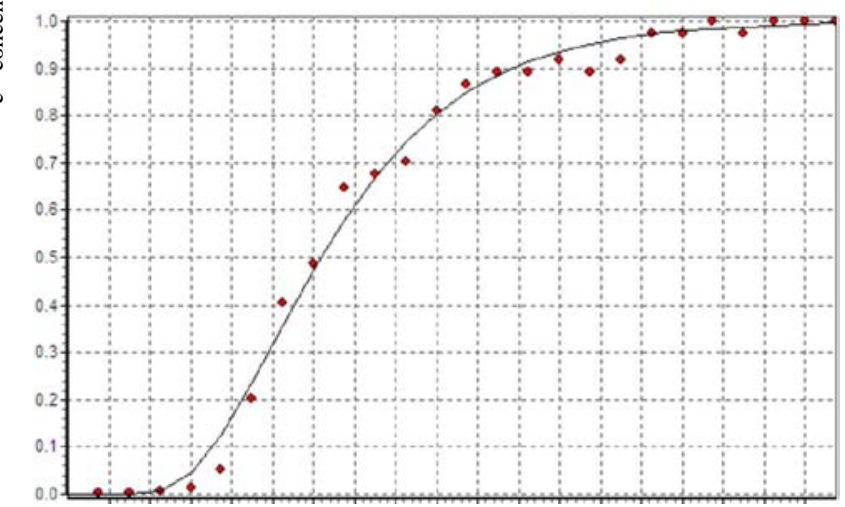

D.

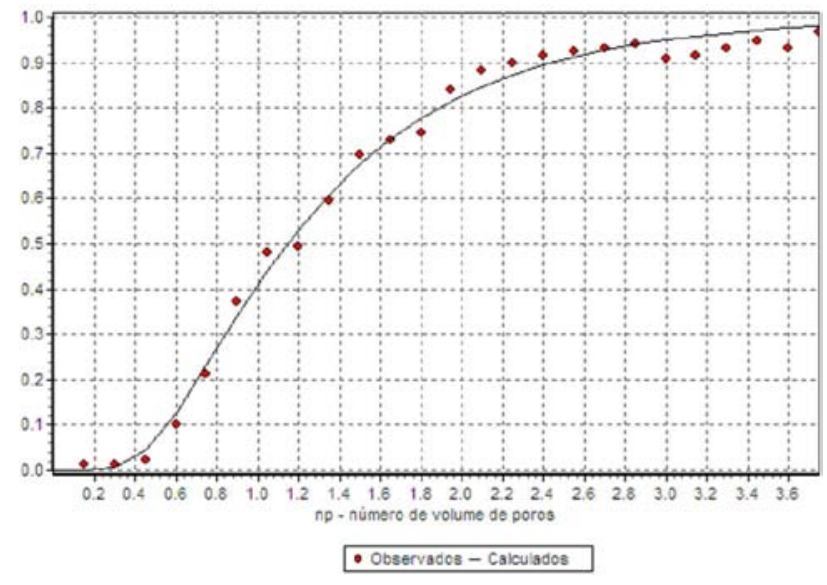

Figura 4. Curvas de efluente para o cálcio (A), magnésio (B), sódio (C) e potássio (D), ajustadas através do programa computacional DISP, para o solo Neossolo Regolítico e água residuária de suinocultura 


\section{CONCLUSÕES}

1. Nos solos lavados com água residuária de esgoto tratado o maior fator de retardamento correspondeu ao sódio no solo Argissolo Vermelho amarelo e magnésio no Neossolo Regolítico.

2. Nos solos lixiviados com água residuária de suinocultura o maior fator de retardamento se referiu ao íon magnésio.

3. Nas colunas com Neossolo Regolítico obteve-se o mais elevado coeficiente de dispersão-difusão.

\section{LITERATURA CITADA}

Agourakis, D. C.; Camargo, I. M. C.; Cotrim, M. B.; Flues, M. Comportamento de zinco e manganês de pilhas alcalinas em uma coluna de solo. Revista Química Nova, v.29, n.5, p.960-964, 2006.

Borges Júnior, J. C. F.; Ferreira, P. A. Equações e programa computacional para cálculo do transporte de solutos do solo. Revista Brasileira de Engenharia Agrícola e Ambiental, v.10, n.3, p.604-611, 2006.

Cavallet, L. E.; Lucchesi, L. A. C.; Moraes, A. de; Schimidt, E.; Perondi, M. A.; Fonseca, R. A. da. Melhoria da fertilidade do solo decorrentes da adição de água residuária da indústria de enzimas. Revista Brasileira de Engenharia Agrícola e Ambiental, v.10, n.3, p.724-729, 2006.

Costa, P. O. da S. Avaliação em laboratório do transporte de contaminantes no solo do aterro sanitário de Sauípe/BA. Rio de Janeiro: PUC, 2002. 171p. Dissertação Mestrado

EMBRAPA - Empresa Brasileira de Pesquisa Agropecuária. Manual de métodos de análise do solo. 2.ed. Rio de Janeiro: Embrapa CNPS, 1997. 247p.

Engler, M. P. C.; Cichota, R.; Lier, Q. J. V.; Bloem, E.; Sparovek, G.; Schnug, E. . An alternative approach for the determination of soil water mobility. Pedosphere, v.18, p.328-334, 2008.

Genuchten, M. T. van; Wierenga, P. J. Solute dispersion coefficients and retardation factors. Soil Science American Society, v.67, p.1025-1054, 1986.

Gomes, E. R. S.; Sampaio, S. C; Corrêa, M. M.; Vilas Boas, M. A.; Alves, L. F. A.; Alves Sobrinho, T. Movimento de nitrato proveniente de água residuária em colunas de solo. Revista Engenharia Agrícola, v.24, n.3, p.557-568, 2004.
Martinez, M. A.; Ramos, V. B. N.; Matos, A. T. de; Oliveira, R. A. de; Costa, S. N. da. Influência da competição catiônica nos valores de fator de retardamento e coeficiente de dispersão-difusão de zinco e cobre no solo. Revista Brasileira de Engenharia Agrícola e Ambiental, v.5, n.2, p.211215, 2001.

Medeiros, S. S. de; Soares, A. A.; Ferreira, P. A.; Neves, J. C. L.; Souza, J. A. de. Utilização de água residuária de origem doméstica na agricultura: Estudo do estado nutricional do cafeeiro. Revista Brasileira de Engenharia Agrícola e Ambiental, v.12, n.2, p.109-115, 2008.

Melo, R. F.; Ferreira, P. A.; Matos, A. T.; Ruiz, H. A.; Oliveira, L. B. Deslocamento miscível de cátions básicos provenientes da água residuária de mandioca em colunas de solo. Revista Brasileira de Engenharia Agrícola e Ambiental, v.10, n.2, p.456-465, 2006.

Neves, R.; Chambel-Leitão, P.; Leitão, P. C. Modelação numérica da circulação da água no solo, o modelo mohid. Pedologia, v.28, p.46-55, 2000.

Nielsen, D. R.; Biggar, J. W. Miscible displacement: III, Theoretical considerations. Soil Science Society of America Proceedings, v.26, n.3, p.216-221, 1962.

Piffer, R. Movimento e degradação de Aldicarb e Sulfona de Aldicarb em dois diferentes solos. Lavras: ESAL, 1989. 99p. Dissertação Mestrado

Santos, A. B.; Fageria, N. K.; Zimmermann, F. J. P. Atributos químicos do solo afetado pelo manejo da água e do fertilizante potássico na cultura de arroz irrigado. Revista Brasileira de Engenharia Agrícola e Ambiental, v.6, n.1, p.1216, 2002.

Santos, H. G.; Jacomine, P. K. T.; Anjos, L. H. C.; Oliveira, V. A.; Oliveira, J. B.; Coelho, M. R.; Lumbreras, J. F.; Cunha, T. J. F. (ed.) Sistema brasileiro de classificação de solos. 2 ed. Rio de janeiro: Embrapa Solos, 2006. 306p.

Santos, J. W. dos; Almeida, F. de A. C.; Beltrão, N. E. de M.; Cavalcante, F. B. Estatística Experimental Aplicada. 2. Edição revisada e ampliada. Campina Grande: Embrapa Algodão/ UFCG, 2008. 461p.

Valocchi, A. J. Describing the transport of ion-exchanging contaminants using an effective kd approach. Water Resource Research, v.20, n.4, p.499-503, 1984. 